\title{
Minas contada em números - A capitania de Minas Gerais e as fontes demográficas (1776-1821)*
}

\author{
Roberta Giannubilo Stumpf ${ }^{\star \star}$
}

Os “mapas da população" produzidos a partir da década de 1770 contribuem para a análise de um período da história de Minas Gerais que foi particularmente importante pelas mudanças vivenciadas em âmbitos muito diversos. Tendo por base as informações destes documentos, o presente artigo analisa as transformações na economia mineira, assim como a redefinição daquela sociedade em um período no qual Minas Gerais ganha um novo perfil, mas mantém seu papel fundamental nas dinâmicas do centro-sul da América portuguesa.

Palavras-chave: Economia mineira. População colonial. Estatística da população. Brasil. Séculos XVIII-XIX.

\footnotetext{
* Artigo produzido no âmbito do projeto internacional População e império. A demografia e os processos estatísticos no ultramar português, 1776-1875 (COLDEMO), financiado pela Fundação para a Ciência e Tecnologia/Portugal.

** Centro de História D’Aquém e D’Além-mar da Faculdade de Ciências Sociais e Humanas, Universidade Nova Lisboa, Lisboa, Portugal (robertastumpf@gmail.com).
} 


\section{Introdução}

Estudar a capitania de Minas Gerais a partir de mapas da população produzidos por autoridades locais nas últimas décadas do século XVIII e nas primeiras do século seguinte é o objetivo central deste artigo. Trata-se de um período de média duração, no qual esta capitania, e a América portuguesa de uma forma global, passou por mudanças em âmbitos muito diversos, embora aqui se dará destaque, devido à tipologia das fontes, sobretudo às de caráter socioeconómico. ${ }^{1}$

A história demográfica e a demografia histórica têm sido amplamente estudadas para as Minas Gerais, com incidência nas áreas temáticas relacionadas à escravidão e à família, sobretudo para o século XIX, ainda que não seja descurado o século precedente. As obras de alguns pesquisadores se destacam pelo seu conjunto, como as dos economistas Francisco Vidal Luna, Iraci del Nero e Herbert Klein, que trabalharam, muitas vezes em parceria, o tema do escravismo nas Minas Gerais, nas suas duas vertentes: social e económica. Desta breve listagem, na qual corremos o risco de cometer injustiças, lembramos ainda o economista Laird Bergard e o historiador Douglas Libby, este também pelo seu interesse, mais recente, pelo estudo da família mineira, ao qual tem se dedicado também Tarcísio Botelho, entre muitos outros.

As fontes utilizadas neste artigo não são inéditas, já foram analisadas por muitos especialistas que, maioritariamente, as tomaram isoladamente e não em seu conjunto. Nossa contribuição está, inversamente, no estudo da capitania de Minas Gerais a partir de uma abordagem panorâmica destes mapas da população e no cruzamento destas fontes com outras coetâneas.

Na primeira parte deste artigo, dedicada ao contexto de produção destes mapas, recorremos às listas e enumeramentos de população das Minas das décadas anteriores, assim como transporemos os limites geográficos da capitania para analisá-los em seu contexto imperial. Com isso, pode-se entender melhor os significados e as especificidades destas fontes, bem como de sua produção a partir de 1776, em seu contexto local.

A análise dos números e das categorias sociais presentes nos mapas será apresentada na segunda e na terceira partes do artigo. As Minas serão compreendidas na sua totalidade sem que sejam descuradas as diversidades em seu interior, sobretudo em duas de suas comarcas, Vila Rica e Rio das Mortes, que apresentaram trajetórias bastante díspares neste período, constituindo por isso importantes estudos de caso sobre os avanços e as quebras populacionais, como também sobre as oscilações económicas.

Em termos historiográficos, ou seja, recorrendo à demografia para esclarecer outras temáticas, a informação recolhida e analisada permite, por um lado, debater alguns marcos da história da capitania mineira e, por outro, retomar temas centrais da história do

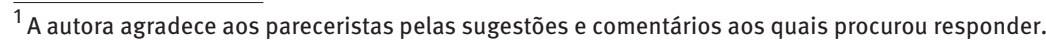


Brasil colonial, debatidos a propósito da conexão entre imigração, taxa de masculinidade e composição étnica da população.

\section{Listas, numeramentos e mapas de população: o século XVIII mineiro}

Assim como em muitos territórios do Império português, em Minas Gerais os numeramentos da população passaram a ser realizados a partir da década de 1770 , enquanto para o período anterior dispomos apenas de listas nominativas. Algumas destas fontes remontam ao início do povoamento da capitania, sobretudo às décadas de 1710 e 1720, quando se introduziu pela primeira vez a cobrança do quinto do ouro (BOTELHO, 2000, 2006). Com a capitação (1736-1750) foi preciso inventariar os proprietários de escravos, já que a cobrança incidia também no número de seus cativos registrados nas intendências duas vezes por ano. ${ }^{2}$ Estas listas já foram em grande medida utilizadas pela historiografia e pelos demógrafos (COSTA, 1979; COSTA; LUNA, 1982), assim como as que foram produzidas posteriormente, como aquela que continha uma relação dos homens mais abonados da capitania, elaborada em 1756 com o propósito de lançar uma contribuição para reconstruir Lisboa destruída por um terremoto um ano antes (AHU/MG Cx: 70, Doc: 41; ALMEIDA, 2010; STUMPF, 2014).

Nem todas as fontes "pré-censitárias" (MARCíLIO, 2004, p. 311) correspondiam a intentos fiscalistas. Após o Concilio de Trento, passaram a ser produzidos pelos párocos os registros de batismos, de casamentos e de óbitos, assim como os registros momentâneos como os róis de confessados. Também os inventários e os testamentos redigidos e armazenados nos cartórios notariais são um manancial riquíssimo de informações para a história social, que podem completar as informações das fontes anteriores (GUEDES; FRAGOSO, 2016, p. 8). Entretanto, somente a partir da década de 1770, na sequência da iniciativa inglesa e concomitantemente à castelhana (ALDEN, 1963), é que começou a produção de cômputos para se conhecerem "os números de vassalos do monarca português em suas conquistas" 3 para melhorar a administração dos territórios ultramarinos. É neste contexto que tais mapas devem ser analisados (SANTOS, 2009), assim como a metodologia pensada para a sua produção, rigorosamente transmitida aos governantes responsáveis por remetê-los às autoridades régias em Lisboa.

0 ano de 1776 destaca-se neste processo de materialização da "aritmética política", 4 ou seja, dos novos intentos da monarquia para produzir um conhecimento quantitativo das populações dos territórios por si administrados. É o que se verifica em Minas e em outros territórios da América portuguesa e da África oriental, nomeadamente Moçambique, já

\footnotetext{
2 Estas listas de matrículas, como ficaram conhecidas, são mais um exemplo de fontes "pré-censitárias" de natureza nominativa. Para Minas ver: AHU/MG Cx:42 Doc:62; Cx:44 Doc:85; Cx:55 Doc:39.

${ }^{3}$ Tal como se referiu o secretário de Estado da Marinha e Ultramar, Martinho de Melo e Castro, ao governador do Maranhão em 1776 (AHU_ACL_CU 009; Cx: 50, D. 4951). Em termos muito semelhantes, dirigia-se, no mesmo ano, ao governador de Minas (CARTA..., 1963, p. 257).

${ }^{4}$ Termo cunhado pelo economista William Petty, em livro publicado em 1690.
} 
autónomo da administração do Estado da Índia (WAGNER, 2009). Entretanto, algumas instruções para a realização de tais cômputos tinham sido recebidas, poucos anos antes, em alguns territórios ultramarinos (MATOS; SOUSA, 2015). Já em 1772, o governador de Luanda os remetia à capital lisboeta, o que foi feito de modo intermitente até 1798, quando os cômputos começaram a ser confecionados com regularidade anual (CURTO; GERVAIS, 2002). Em 1771, o governador de Goiás, Barão de Mossamede, recebeu instruções com idêntico teor, mas passados dois anos narrava as dificuldades encontradas para remeter no prazo exigido a relação dos moradores daquela capitania (ALENCASTRE, 1864, p. 257). Segundo ele:

[...] logo que tomou posse mandou cartas circulares a todos os párocos, para mandarem as listas dos seus fregueses, na conformidade do método que recebi nas minhas instruções, (mas) alguns por força da ignorância o não compreenderam, e outros esperaram o tempo da desobriga para o executarem com mais exação (AHU/GO AHU_ACL_CU_008, Cx: 27, D. 1734).

A exemplificar a alteração que promoveu as ordens emitidas na década de 1770, sobretudo na metodologia e na natureza das informações a serem recolhidas, lembramos um mapa de Minas, produzido poucos anos antes, em 1767, cujo título sintetiza a riqueza de dados mas também a confusão gerada quando se inserem dados de qualidade tão diversa em uma mesma tabela, sem uma aparente correspondência entre si: "Fogos, Filhos, Filhas, Escravos, e Escravas, Pardos forros, e pretos forros, agregados, clérigos, Almas, Freguesias, Vigários, com declaração do que pertence a cada termo e total, e geral de toda a capitania de Minas Gerais, tirado no anno 1767". ${ }^{5}$ Ao que parece, o mapa foi remetido para o Reino pelo governador Luís Diogo Lobo da Silva, que a ele juntou mais oito mapas ${ }^{6}$ que fornecem um raio $X$ da capitania. As razões para a sua produção e envio são desconhecidas, mas é muito provável que tenha partido da iniciativa do próprio governador, cuja experiência administrativa certamente apurou a sua perceção de que muitas dificuldades poderiam ser resolvidas, ou ao menos amenizadas, quando as diretrizes metropolitanas fossem formuladas a partir de informações quantitativas. A este desejo em ser útil à monarquia portuguesa, podemos somar a ambição do governador em ser remunerado pelos seus serviços (SOUZA, 2006). De qualquer forma, o mapa que fornece dados populacionais trazia uma metodologia "antiga”, própria das fontes produzidas por párocos. Um ano depois, Melo e Castro voltava a solicitar ao governador que fornecesse o número de habitantes da capitania, dividindo-os em "classe”, género e categorias etárias (STUMPF, 2011, p. 217).

As tabelas estatísticas da população, que compõem a série mais importante que dispomos para a capitania de Minas Gerais, foram solicitadas por Melo e Castro, em 1776, ao então governador de Minas, D. António de Noronha. Atendendo à pressa exigida na remessa, o capitão-general, em janeiro de 1778, remetia

\footnotetext{
${ }^{5}$ Agradeço a Mar García Arenas pela disponibilização da cópia deste mapa, com ligeiras modificações, existente no Instituto dos Arquivos Nacionais/Torre do Tombo, Ministério dos Negócios Eclesiásticos e Justiça (MNEJ), Mç. 67, Cx. 56, no 6.

${ }^{6}$ AHU/MG CX: 98 Doc: 53.
} 
[...] o Mapa dos habitantes desta capitania com as Relações que os mesmos ouvidores das respetivas comarcas me enviaram, o qual não vai com aquela exação [sic] que eu desejo, não porque os ditos ministros deixassem de entender as ordens, que para este efeito lhes distribui, mas sim talvez por eu lhes não explicar mais miudamente as circunstâncias precisas para o referido efeito (AHU / MG - Cx: 112, Doc: 11).

Noronha humildemente reconhecia que, quiçá, o problema estava em não saber transmitir as informações desta nova estratégia com a celeridade que a missão exigia. Também o governador do Maranhão, em setembro de 1776, queixava-se do ritmo exigido para o cumprimento das ordens, afinal, "para as relações serem exatas como devem, se hão de correr aquelas freguesias todas, e com muita miudeza” (AHU_ACL_CU 009; Cx: 50, D. 4951). Tarefa difícil, evidentemente, em se tratando de um território cuja dimensão era ainda maior do que a de Minas. A periodicidade anual dificilmente poderia ser atendida quando se dependia de outras autoridades, como ouvidores e párocos, para recolher as informações "com toda a clareza”. Muitas vezes era preciso interromper os recenseamentos para cumprir ordens régias ainda mais urgentes, como explica o governador de Minas, D. Bernardo de Lorena, na correspondência que mantém com D. Rodrigo de Sousa Coutinho de 1798 a 1800 (AHU/MG Cx: 144 Doc: 18; Cx: 147 Doc: 55; Cx: 154 Doc: 42).

Há certamente outras razões para explicar porque não foram produzidas tantas fontes sobre a população como pretendido. Todavia, para o caso mineiro, os mapas confecionados em $1776,{ }^{7} 1786,1805,1808$ e aquele ainda mais completo referente ao ano de $1821^{8}$ nos permitirão estabelecer uma análise do crescimento e das mudanças socioeconómicos deste território ao longo destes 45 anos.

As fontes demográficas datadas de 1776 são, sem sombra de dúvida, as mais importantes que dispomos para Minas colonial. Trata-se de um conjunto composto por cinco mapas, um para cada comarca e um referente a toda a capitania que sintetiza em larga medida as informações dos anteriores. Esta opção em individualizar os mapas por comarca, território de jurisdição de um magistrado que servia como ouvidor, pode ser explicada em função da própria logística da recolha dos dados, uma vez que estes eram obtidos pelo ouvidor junto aos párocos para então repassá-los ao governador. 0 mesmo se verifica com os mapas produzidos para a Bahia, capitania que guardava com Minas a singularidade de ter em seu território mais de uma comarca. Entretanto, no caso baiano, o percurso da coleta e difusão dos dados, párocos-ouvidores-governador, fica ainda mais evidente ao se subdividirem as informações pelas freguesias (território da jurisdição eclesiástica dos párocos) que pertenciam a cada uma das comarcas (AHU_ACL_CU_005-01, Cx. 55, Doc 10700-10701). Esta opção na exposição dos dados nos permite visualizar com maior detalhamento a distribuição dos habitantes pelo território, menos visíveis nos mapas para as Minas, dos quais só se pode dispor da informação agregada por comarcas, de maior amplitude geográfica do que as suas freguesias ou vilas, que totalizavam oito em 1718 e 15 em 1822.

\footnotetext{
${ }^{7}$ AHU /MG - Cx: 112, Doc: 11 .

${ }^{8}$ Eschwege (1899, p. 774).
} 
De qualquer forma, é importante dizer que esta divisão por comarcas, que surge também no mapa geral da capitania de 1821, possibilita obter um panorama da realidade mineira bem mais minucioso do que, por exemplo, as fontes de 1786,1805 e $1808,{ }^{9}$ que fornecem apenas os cômputos da população global da capitania dividindo-a por "cor", ${ }^{10}$ género e condição jurídica. Minas era uma unidade administrativa reconhecida por todas as autoridades e por seus habitantes, mas as suas quatro comarcas guardavam entre si muitas diferenças que podem ser mais bem observadas quando tratadas isoladamente. A partir da década de 1770, quando muitos “ilustrados" (americanos portugueses ou reinóis) produziram suas memórias políticas, geográficas, físicas... de Minas, com o intuito de contribuir para a monarquia no fomento económico, também optaram por fazer suas descrições referenciando a estas mesmas divisões administrativas. Foram elas também que guiaram o cartógrafo José Joaquim da Rocha na feitura do primeiro mapa da capitania e dos quatro que correspondem às suas comarcas, em 1776 (ROCHA, 1995).

Foi em 1714 que as três primeiras comarcas foram demarcadas, Vila Rica, Rio das Mortes e Rio das Velhas/Sabará, e seis anos depois esta última foi desmembrada por ocasião da criação da comarca do Serro Frio (MORAES, 2007). Apesar da ampla extensão do território mineiro, a população se concentrou nos centros urbanos, sobretudo nas capitais das comarcas, muito próximas entre si. ${ }^{11}$ Este adensamento populacional nas vilas, característico de Minas, somado ao das instituições régias e locais que o acompanhavam, contribuiu para que os sertões, sobretudo das comarcas mais extensas (Rio das Velhas e Serro Frio) ficassem pouco habitados e distantes da imposição das diretrizes régias, ao menos no período inicial. Décadas mais tarde, esta configuração foi alterada, por exemplo, na comarca do Rio das Velhas, com a criação em 1798 da vila interiorana de Paracatu do Príncipe, limítrofe com a capitania de Goiás.

\section{Os anos de 1776-1821: crescimento populacional}

Começamos então por analisar Minas em seu conjunto tal como nos possibilitam os dados contidos nos mapas de 1776 e 1821, que em comum discriminam a população por cor e género. Neste espaçamento temporal, conforme se pode ver na Tabela 1, a população da capitania de Minas Gerais cresceu 60,7\%, passando de 319.769 para 514.038 habitantes. Trata-se de um aumento significativo, mas muito aquém da média do território brasileiro neste mesmo período de 45 anos (126,7\%). À primeira vista, este desfasamento pode sugerir um recuo da sua atividade económica devido à queda da extração do ouro. Entretanto, como já mostrou a historiografia sobre as Minas, a capitania conseguiu passar pela crise da produção aurífera sem ser significativamente prejudicada, em função da diversidade

\footnotetext{
${ }_{9}^{9}$ Revista do Arquivo Público Mineiro (1899, p. 294-296).

${ }^{10}$ Usamos a expressão cor para reportar às classificações utilizadas nas próprias fontes: branco/as, pardo/as, mulato/as e pretos/as.

${ }^{11}$ Vila Rica do Ouro Preto, Vila de São João del Rey, Vila de Nossa Senhora da Conceição do Sabará e Vila do Príncipe.
} 
económica e produtiva que apresentou desde o início de sua história (LINHARES, 1979; FURTADO, 2009; ALMEIDA, 2010).

Em termos populacionais, Minas Gerais conseguiu se manter como a região mais populosa do Brasil até a independência, sendo ultrapassada apenas pela província da Bahia em 1835 (BOTELHO, 2013). Na Tabela 1, observa-se a evolução deste crescimento, comparando-o com aquele verificado na população total do Brasil. Apesar dos ritmos diferentes, a capitania continuou a acolher parcela considerável da população brasileira em seu território, apresentando uma redução deste porcentual apenas no século XIX. ${ }^{12}$

TABELA 1

Crescimento populacional

Capitania de Minas Gerais e Brasil - 1776-1821

\begin{tabular}{|c|c|c|c|c|c|}
\hline \multirow[b]{2}{*}{ Anos } & \multicolumn{2}{|c|}{ Minas Gerais } & \multicolumn{2}{|c|}{ Brasil } & \multirow{2}{*}{$\begin{array}{c}\text { Participação de } \\
\text { Minas Gerais no total } \\
\text { da população do Brasil } \\
(\%)\end{array}$} \\
\hline & $\begin{array}{c}\text { População } \\
\text { (habitantes) }\end{array}$ & $\begin{array}{l}\text { Crescimento } \\
\text { anual da } \\
\text { população (\%) }\end{array}$ & $\begin{array}{c}\text { População } \\
\text { (habitantes) }\end{array}$ & $\begin{array}{l}\text { Crescimento } \\
\text { anual da } \\
\text { população (\%) }\end{array}$ & \\
\hline 1776 & 319.769 & - & 1.426 .965 & - & 22,4 \\
\hline 1786 & 393.968 & 2,1 & 1.726 .940 & 1,9 & 22,8 \\
\hline 1805 & 407.504 & 0,2 & 2.308 .304 & 1,5 & 17,7 \\
\hline 1808 & 433.049 & 2,0 & 2.424 .463 & 1,7 & 17,9 \\
\hline 1821 & 514.038 & 1,3 & 3.235 .549 & 2,2 & 15,9 \\
\hline \multicolumn{6}{|l|}{$\Delta$} \\
\hline $\begin{array}{l}1776-1821 \\
(\%)\end{array}$ & 60,7 & 1,1 & 126,7 & 1,8 & 16,6 \\
\hline
\end{tabular}

Fonte: AHU /MG - Cx: 112, Doc: 11; Eschwege (1899, p. 774); Revista do Arquivo Público Mineiro (1899, p. 294-296); Botelho (2013).

Entretanto, se Minas Gerais apresentou um crescimento populacional significativo, este não pode ser comparado ao do período anterior. Logo no princípio do século XVIII, o volume de ouro extraído, ou a notícia de que este avultava, atraiu para aquele território uma quantidade enorme de pessoas. Nas palavras de Augusto de Lima Júnior (1978, p. 32), “os anos de 1701 e 1702 caracterizam-se na história do povoamento, pelas mais audazes aventuras de deslocamentos humanos de que se há memória”. Todavia, o crescimento se deu verdadeiramente nas décadas de 1740-1760, auge da produção aurífera. Outros cálculos mostram que de 1710 a 1742, a população em Minas cresceu 623\%, mas, entre 1710 e 1776, o aumento foi de cerca de $1.000 \%$ (MÓL, 2004, p. 1)! Em termos de crescimento médio anual, o período de 1721-1722 a 1776 apresentou uma taxa média de 2,3\% e 2,4\% (BOTELHO, 2000,18). Nos dez anos seguintes, esta taxa reduziu-se ligeiramente para $2,1 \%$, segundo nossos cálculos, embora apresentasse uma queda bastante acentuada até 1805, para então voltar a se recuperar no período 1805-1821, com 1,1\% de taxa de crescimento médio anual, muito abaixo do ritmo de crescimento populacional dos setecentos (Tabela 1).

Se analisarmos a população mineira segundo critérios de cor, género e condição jurídica, também podemos observar como o crescimento após 1776 foi qualitativamente

\footnotetext{
${ }^{12}$ Percentual que se aproxima aos cálculos de Alden (2000, p. 308), segundo o qual Minas Gerais acolhia 19,7\% da população brasileira no início do século XIX. Para Boris Fausto (1995, p. 137-139), no ano de 1819, esta porcentagem era de 17,5\%.
} 
diferente daquele verificado nas primeiras décadas dos setecentos. Nestas, o crescimento avassalador deveu-se sobretudo à imigração de brancos e escravos do sexo masculino, ainda que alguns pudessem já ter residido em outras capitanias. Mas neste período de 45 anos que estamos analisando, o crescimento ocorreu por outras razões, como, por exemplo, pelo aumento da população feminina em 93\% (Tabela 2). De 120.128, em 1776, as mulheres passaram para 232.404 habitantes em 1821, representando, para os anos respetivos, 37,6\% e 45,2\% da população geral da capitania. As pretas, que em 1776 formavam o grupo maioritário dentre as mulheres, foram ultrapassadas ligeiramente pelas pardas/mulatas, cujo crescimento foi o mais surpreendente de todos os grupos divididos por cor/sexo da população de Minas no período considerado. ${ }^{13}$

TABELA 2

População, por género, segundo cor

Capitania de Minas Gerais - 1776-1821

\begin{tabular}{|c|c|c|c|c|c|c|c|}
\hline \multirow{2}{*}{ Cor } & \multicolumn{2}{|c|}{ Homens } & \multicolumn{2}{|c|}{ Mulheres } & \multirow{2}{*}{$\begin{array}{c}\text { Razão de } \\
\text { sexo (1) }\end{array}$} & \multicolumn{2}{|c|}{ Total } \\
\hline & $\mathrm{N}$ & $\%$ & $\mathrm{~N}$ & $\%$ & & $\mathrm{~N}$ & $\%$ \\
\hline \multicolumn{8}{|l|}{1776} \\
\hline $\begin{array}{l}\text { Brancos } \\
\text { Pardos (2) } \\
\text { Pretos }\end{array}$ & $\begin{array}{l}41.677 \\
40.793 \\
117.171\end{array}$ & $\begin{array}{l}13,0 \\
12,8 \\
36,6\end{array}$ & $\begin{array}{l}28.987 \\
41.317 \\
49.824\end{array}$ & $\begin{array}{r}9,06 \\
12,92 \\
15,58\end{array}$ & $\begin{array}{r}143,78 \\
98,73 \\
235,16\end{array}$ & $\begin{array}{r}70.664 \\
82.110 \\
166.995\end{array}$ & $\begin{array}{l}18,88 \\
25,67 \\
53,33\end{array}$ \\
\hline Total & 199.641 & 62,4 & 120.128 & 37,6 & 166,19 & 319.769 & 100,00 \\
\hline \multicolumn{8}{|l|}{1821} \\
\hline $\begin{array}{l}\text { Brancos } \\
\text { Mulatos } \\
\text { Pretos }\end{array}$ & $\begin{array}{r}70.262 \\
81.964 \\
129.408\end{array}$ & $\begin{array}{l}13,7 \\
15,9 \\
25,2\end{array}$ & $\begin{array}{l}60.785 \\
89.578 \\
82.041\end{array}$ & $\begin{array}{l}11,82 \\
17,42 \\
15,95\end{array}$ & $\begin{array}{r}115,59 \\
91,5 \\
157,73\end{array}$ & $\begin{array}{l}131.047 \\
171.542 \\
211.449\end{array}$ & $\begin{array}{l}25,49 \\
33,36 \\
41,14\end{array}$ \\
\hline Total & 281.634 & 54,8 & 232.404 & 45,2 & 121,18 & 514.038 & 100,00 \\
\hline
\end{tabular}

Fonte: AHU /MG - Cx: 112, Doc: 11; Eschwege (1899, p. 774).

(1) Número de homens para cada 100 mulheres.

(2) Do ponto de vista das categorias raciais, a única diferença entre os mapas de 1776 e 1821 refere-se à utilização do vocabulário pardos/as e mulatos/as, respectivamente, para representar o mesmo grupo.

TABELA 3

Crescimento da população, por género, segundo cor Capitania de Minas Gerais - 1776-1821

\begin{tabular}{|c|c|c|c|c|c|c|}
\hline \multirow[t]{2}{*}{ Cor } & \multicolumn{2}{|c|}{ Homens } & \multicolumn{2}{|c|}{ Mulheres } & \multicolumn{2}{|c|}{ Total } \\
\hline & $\mathrm{N}$ & $\%$ & $\mathrm{~N}$ & $\%$ & $\mathrm{~N}$ & $\%$ \\
\hline $\begin{array}{l}\text { Brancos } \\
\text { Pardos/mulatos } \\
\text { Pretos }\end{array}$ & $\begin{array}{r}+28.585 \\
+41.171 \\
+12.237\end{array}$ & $\begin{array}{r}68,6 \\
100,8 \\
10,5\end{array}$ & $\begin{array}{l}+31.798 \\
+48.261 \\
+32.217\end{array}$ & $\begin{array}{r}109,7 \\
116,8 \\
64,7\end{array}$ & $\begin{array}{l}+60.383 \\
+89.432 \\
+44.459\end{array}$ & $\begin{array}{r}89.1 \% \\
108.92 \% \\
26.6 \%\end{array}$ \\
\hline Total & +81.993 & 42,2 & +112.276 & 93,39 & +194.269 & \\
\hline
\end{tabular}

Fonte: AHU /MG - Cx: 112, Doc: 11; Eschwege (1899, p. 774).

Por sua vez, conforme se pode observar na Tabela 3, a população masculina cresceu 42,2\%, passando de 199.641 para 281.634 indivíduos, entre 1776 e 1821; porém, sua participação no total da população mineira diminuiu de $62,4 \%$ para $54,8 \%$, no mesmo

\footnotetext{
$\overline{13}$ A terminologia aqui empregada reproduz exatamente aquela que aparece nas fontes demográficas que estamos analisando: brancos/brancas; pardos/pardas ou mulatos/mulatas e pretos/pretas.
} 
período (Tabela 2). A composição racial deste grupo continuou a contar com a predominância dos pretos, embora com uma redução significativa de 11,4 pontos percentuais devido ao aumento do número de brancos e, sobretudo, de pardos, que em 1776 eram o grupo minoritário entre os homens, mas, no mapa de 1821, com a designação de mulatos, já estavam em maior número do que os brancos (Tabela 2).

Para que a média de crescimento da sociedade mineira $(60,7 \%)$ fosse alcançada neste período (Tabela 1), vimos que o aumento da população feminina contribuiu significativamente. Do ponto de vista racial, sem divisão por género, foi o grupo dos pardos/mulatos que revelou maior crescimento, com $108,8 \%$, seguido dos brancos com $89,1 \%$ e dos pretos com apenas $26,6 \%$ (Tabela 3 ).

Entretanto, se a curva de crescimento dos grupos divididos por sexo e cor foi bastante desigual, o peso numérico de cada um em relação à população total das Minas manteve-se praticamente o mesmo (Tabela 2). Ou seja, a sociedade mineira continuou a ser composta maioritariamente por homens e com predomínio dos mesmos grupos raciais, nesta ordem: preto, pardo e branco. Todavia, estas permanências não escondem uma mudança significativa, visível quando dividimos os grupos raciais por género, conforme se observa na Tabela 3. Aquela desigualdade numérica entre homens e mulheres existente em 1776, 45 anos depois se reduziu consideravelmente no interior de todos os grupos raciais, sobretudo pelo aumento de mais de $100 \%$ das pardas, das brancas e dos pardos (nesta ordem) e pelo aumento muito pouco expressivo dos pretos (10,5\%).

De forma geral, a população de Minas cresceu, mas em um ritmo muito menos acentuado do que o daquele verificado, principalmente, nas décadas de 1740-1770. Porém, para além da diferença no ritmo deste crescimento, o mais interessante é a forma como ele se processou. Antes de tudo observamos uma elevação numérica substancial das mulheres daquela sociedade, conforme já referido, não obstante os homens continuarem a ser quantitativamente superiores. Em termos proporcionais, as mulheres, que antes totalizavam cerca de $1 / 3$ da população, passaram a representar $45,2 \%$, sendo que esta "quase" igualdade numérica com os homens traduz, por isso, a diminuição da imigração, por esta ser maioritariamente masculina.

Em relação aos brancos, as mulheres que antes correspondiam a 9,06\% da sociedade mineira, mais de quatro décadas depois passaram a ser $11,82 \%$, enquanto o mesmo índice dos homens brancos se manteve praticamente inalterado, contribuindo para uma redução significativa da razão de sexo neste grupo racial. Se em 1821 havia mais 31.798 mulheres brancas, ou seja, um aumento de quase $110 \%$ em relação a 1776 , isto ocorreu devido a um crescimento natural, já que as mulheres brancas raramente imigravam no período considerado. 0 mesmo se pode dizer das mulheres pretas, cujo número se elevou 6,5 vezes a mais do que o dos pretos que, como vimos, tiveram um incremento residual de "apenas" $10 \%$. 0 aumento do número de brancos e pretos do sexo masculino explica-se menos pelo crescimento natural do que pela imigração. Todavia, por esta não ocorrer na mesma intensidade de outrora, acabou por reduzir o ritmo de crescimento destes grupos. 
A situação apresentada pelos pardos/as é significativamente diferente. Por se tratar de um grupo racial de origem essencialmente "americana", seu aumento de 108,9\% no período, muito superior aos $26,6 \%$ dos pretos/as e um pouco acima dos brancos $(89,1 \%)$, deu-se de forma natural (Tabela 3). É pouco provável que tenham migrado de outras capitanias, pois no intervalo de tempo considerado Minas Gerais não apresentou nenhum atrativo economicamente relevante que justificasse tal fato. Mas neste grupo "racial", ao contrário dos demais, não foi somente o número de mulheres que subiu de forma estrondosa. Também os homens (livres ou escravos) contribuíram para a elevação quantitativa do grupo e praticamente no mesmo ritmo, um sinal muito claro de que se trata de um crescimento natural (BUCCIFERRO, 2103, p. 300). De qualquer forma, considerando a razão de género (Tabela 2), a sociedade mineira, tomada em seu conjunto, tinha 166 homens para 100 mulheres em 1776, índice que dimimuiu para 121 homens em 1821.0 predomínio continuava a ser do sexo masculino, como se vê, mas as mulheres elevaram seu contingente consideravelmente.

No período estudado, para além desta maior feminização da sociedade, Minas Gerais foi se tornando cada vez mais mestiça, termo inexistente nos mapas analisados, mas que nos parece bem mais preciso do que a designação pardo/a. Ainda assim, apesar da sua imprecisão, entendemos que, na época, sua utilização se referia essencialmente aos mulatos, terminologia que será empregada no mapa de 1821, corroborando a nossa ideia de que a mestiçagem mais comum naquela região teria ocorrido entre os grupos raciais preto e branco, como tem mostrado também a historiografia (FURTADO, 2009). A título de nota, o vocábulo índio aparece apenas no mapa de 1786 para designar 917 indivíduos, acrescentados à tabela apenas ao final, juntamente com um grupo denominado sem detalhe. Também no mapa de 1823, que foge à cronologia deste estudo, o termo é utilizado demonstrando, talvez, o desinteresse do governo português em reconhecê-los como grupo, apesar das mudanças legislativas dos setecentos. É possível, portanto, que a integração individual de ameríndios na população oficial de Minas seja obscurecida pela terminologia.

Como vimos, as características do crescimento populacional da capitania de 1776 a 1821 divergem daquele verificado nas primeiras décadas dos setecentos, quando para aqueles "sertões" se dirigiram jovens brancos, oriundos sobretudo da região do Minho, assim como africanos vendidos para ali trabalhar como mão de obra escrava. Entretanto, para que a capitania atingisse, já na segunda metade do século XVIII, a reputação de ser a mais populosa da América portuguesa, a miscigenação teve desde então um peso importantíssimo (FURTADO, 2009). Prova disso é a progressiva elevação do contingente de homens de cor, escravos ou livres, africanos ou crioulos, para usar a terminologia da época. É claro que isso não era uma característica exclusiva desta capitania (RUSSELL-WOOD, 2005, p. 19), mas não há como negar que em Minas Gerais esses homens representavam cada vez mais uma parcela significativa, como observou o memorialista José Joaquim da Rocha, em 1776 (ROCHA, 1995). De fato, o aumento do número de pardos e a redução em termos absolutos dos pretos não alteraram os números relativos dos homens de cor $(74,5 \%)$, mas, 
se antes a diferença entre estes grupos era de $27,66 \%$, em 1821 passou a ser de $7,78 \%$ (Tabela 2). 0 acréscimo dos pardos deveu-se à intensa miscigenação que teve lugar em Minas desde os seus primórdios, incentivada posteriormente pelo acréscimo da população feminina, em particular das pardas, que naquela região, quando cativas, ganhavam com mais facilidade o estatuto de livres.

Resta então nos perguntarmos sobre a condição jurídica destes homens de cor. Este é um aspecto essencial para se entender qualquer sociedade escravista, como era a mineira, mas nos mapas produzidos em 1776 apenas os das comarcas de Vila Rica e de Sabará apresentam esta categoria social. Iremos, então, recorrer àqueles publicados pela Revista Arquivo Público Mineiro, relativos aos anos de 1786, 1805, 1808 e 1821, que fornecem esta informação distinguindo pardos/mulatos e pretos, subdividindo-os conforme o género. As tabelas apresentadas a seguir foram produzidas de forma a sistematizar estes dados com o objetivo de observar as transformações da sociedade mineira sob este aspecto, que já despertou, talvez mais do que qualquer outro, o interesse da historiografia (por todos, BOTELHO, 2000; LIBBY, 2007).

TABELA 4

População cativa, segundo género

Capitania de Minas Gerais - 1786-1821

\begin{tabular}{|c|c|c|c|c|}
\hline Género & Pardos & Pretos & $\begin{array}{c}\text { Total da população } \\
\text { escrava }\end{array}$ & $\begin{array}{c}\text { Total dapopulação de } \\
\text { Minas Gerais }\end{array}$ \\
\hline \multicolumn{5}{|l|}{1786} \\
\hline Homens & 9.879 & 106.412 & $\begin{array}{r}116.291 \\
(66,78 \%)\end{array}$ & \\
\hline Mulheres & 10.497 & 47.347 & $\begin{array}{r}57.844 \\
(33,22 \%)\end{array}$ & \\
\hline $\begin{array}{l}\text { Total } \\
\text { Cor }\end{array}$ & $\begin{array}{r}20.379 \\
(11,70 \%) \\
\end{array}$ & $\begin{array}{r}153.759 \\
(88,29 \%) \\
\end{array}$ & $\begin{array}{r}174.135 \\
(48,00 \%) \\
\end{array}$ & $\begin{array}{r}393.698(1) \\
(100,00 \%) \\
\end{array}$ \\
\hline \multicolumn{5}{|l|}{1805} \\
\hline Homens & 12.307 & 112.612 & $\begin{array}{l}124.919 \\
(66,17 \%)\end{array}$ & \\
\hline Mulheres & 12.690 & 51.167 & $\begin{array}{r}63.857 \\
(33,83 \%)\end{array}$ & \\
\hline $\begin{array}{l}\text { Total } \\
\text { Cor }\end{array}$ & $\begin{array}{r}24.997 \\
(13,24 \%)\end{array}$ & $\begin{array}{r}163.779 \\
(86,76 \%) \\
\end{array}$ & $\begin{array}{r}188.776 \\
(46,38 \%) \\
\end{array}$ & $\begin{array}{r}407.004 \\
(100,00 \%) \\
\end{array}$ \\
\hline \multicolumn{5}{|l|}{1808} \\
\hline Homens & 7.857 & 86.849 & $\begin{array}{r}94.706 \\
(63,65 \%)\end{array}$ & \\
\hline Mulheres & 7.880 & 46.186 & $\begin{array}{r}54.066 \\
(36,35 \%)\end{array}$ & \\
\hline $\begin{array}{l}\text { Total } \\
\text { Cor }\end{array}$ & $\begin{array}{r}15.737 \\
(10,58 \%) \\
\end{array}$ & $\begin{array}{r}133.035 \\
(89,42 \%) \\
\end{array}$ & $\begin{array}{r}148.772 \\
(34,35 \%) \\
\end{array}$ & $\begin{array}{r}433.049 \\
(100,00 \%) \\
\end{array}$ \\
\hline \multicolumn{5}{|l|}{1821} \\
\hline Homens & 12.105 & 104.115 & $\begin{array}{l}116.220 \\
(63,9 \%)\end{array}$ & \\
\hline Mulheres & 9.772 & 55.890 & $\begin{array}{r}65.612 \\
(36,1 \%)\end{array}$ & \\
\hline $\begin{array}{l}\text { Total } \\
\text { Cor }\end{array}$ & $\begin{array}{r}21.887 \\
(12,03 \%)\end{array}$ & $\begin{array}{r}160.005 \\
(87,97 \%)\end{array}$ & $\begin{array}{r}181.882 \\
(35,38 \%)\end{array}$ & $\begin{array}{r}514.038 \\
(100,00 \%)\end{array}$ \\
\hline
\end{tabular}

Fonte: AHU /MG - Cx: 112, Doc: 11; Eschwege (1899, p. 774); Revista Arquivo Público Mineiro (1899, p.294-296).

(1) Se contabilizarmos a população sem detalhe e os índios (aparecem à parte no mapa), a porcentagem da população escrava seria inferior: $44,23 \%$. 
Não nos iremos furtar à análise destes indicadores, apesar de eles já terem sido, em larga medida, analisados em outros trabalhos. 0 primeiro diz respeito à diminuição da participação dos escravos na população global, que, em 1786, representavam quase $50 \%$, passando para pouco mais de um terço, em 1821. No período de 1805 a 1808, os cativos chegaram a perder 12 pontos percentuais na sociedade mineira, uma queda que pode ser observada em todos os grupos escravos, com redução de 4.810 mulheres pardas, 4.981 mulheres pretas e 4.450 homens pardos. 0 mais revelador é a diminuição de 25.763 homens pretos cativos, indicando uma contração no período da importação de escravos africanos aparentemente resultante do recuo da atividade económica. Ainda assim, não convém acentuar demasiadamente o impacto desta “crise”, já que Minas continuou a ter em 1808 o maior plantel de escravos em termos absolutos da América portuguesa (BOTELHO; PAIVA, 2008, p. 13-14), mantendo esta posição até a abolição da escravatura (KLEIN; LUNA, 2010, p. 181-186). A chegada da Corte no Rio de Janeiro, em 1808, certamente contribuiu para a retomada do crescimento do número de escravos, necessários a partir do momento em que Minas Gerais se tornou um dos polos abastecedores da nova capital do Império português.

Todavia, apesar de apresentar o maior contingente em termos absolutos de cativos da América portuguesa, a sociedade mineira estava longe de ser maioritariamente escrava, sobretudo porque a quantidade de homens/mulheres livres continuava a aumentar paulatinamente, com destaque para a contribuição das alforrias para isto. Algo que já foi muito realçado e debatido pela historiografia sobre Minas Gerais, que, se está de acordo quanto a ser esta uma especificidade da capitania, diverge em muito quanto às suas explicações (PAIVA, 1995; LIBBY, 2003; STUMPF, 2014).

Enfim, o conjunto dos dados compulsados permite formular hipóteses mais gerais. Sabemos que entre a população imigrante forçada de escravos africanos predominavam largamente os homens, marca ainda mais acentuada entre os migrantes europeus, que eram esmagadoramente homens solteiros, jovens e naturais do Entre Douro e Minho (LIVI-BACCI, 2002; MONTEIRO, 2009). Podemos assim considerar que as taxas de masculinidade entre as populações branca e negra traduzem de forma muita direta a imigração; consequentemente, seu declínio em termos relativos ao longo do período estudado expressa não apenas a quebra da imigração, mas também, porque acompanhado de algum acréscimo de valores absolutos, o crescimento natural da população. Ou seja, com algum exagero, podemos sugerir que o crescimento natural da população se encontra mais próximo dos números relativos à população feminina. 0 facto de isso corresponder ao aumento, em termos tanto absolutos como relativos, do número de mulheres brancas e mulatas e, sobretudo, à diminuição da proporção de escravos e de negros sugere que a reprodução biológica da população mineira, resultado quantitativo agregado de diversos processos de reprodução social e das mutáveis classificações de cor, se traduzia num crescimento da população livre e mulata. E, claro, da proporção de mulheres. Enfim, voltamos a defrontar, sem possibilidade de recuo, o tema da miscigenação. De algum modo, confrontar duas comarcas mineiras no período em análise traduz isso mesmo. 


\section{As comarcas de Vila Rica e do Rio das Mortes}

Até agora temos lidado com dados globais da capitania por ser este o objetivo central a que nos propomos. Porém, não podemos esquecer que as comarcas guardavam grandes diferenças entre si, as quais podem ser notadas, inclusive, na forma como elas vivenciaram as mudanças deste período (1776-1821). Por esta razão, propomos como exercício analítico observar os dados referentes a duas comarcas justamente por apresentarem trajetórias opostas: com Vila Rica a perder sua projeção e apresentar um recuo demográfico de cerca de 4\%; e Rio das Mortes a ganhar visibilidade em função do seu dinamismo económico e ter um aumento populacional de $158 \%$ (Tabelas 5 e 6 ).

Segundo Herculano Mathias, que editou o recenseamento de 1804 da capital da comarca de Vila Rica, de igual nome, esta Vila atravessava uma fase de estagnação, sendo este também o testemunho de John Mawe para quem a Vila conservava em 1809 "uma sombra do (seu) antigo esplendor" (MATHIAS, 1969, p. VII-IX). Entretanto, se podemos falar em contração económica, não parece que a comarca tenha passado por uma fase propriamente nebulosa. Como lembra Mathias, Vila Rica manteve-se como a capital administrativa e provavelmente ali continuavam a residir famílias com alguma fortuna.

TABELA 5

População, por género, segundo cor

Comarca de Vila Rica - 1776-1821

\begin{tabular}{|c|c|c|c|c|c|}
\hline \multirow{2}{*}{ Cor } & \multicolumn{2}{|c|}{ Homens } & \multicolumn{2}{|c|}{ Mulheres } & \multirow{2}{*}{$\begin{array}{c}\text { Razão de } \\
\text { sexo (1) }\end{array}$} \\
\hline & $\mathrm{N}$ & $\%$ & $\mathrm{~N}$ & $\%$ & \\
\hline \multicolumn{6}{|l|}{1776} \\
\hline Brancos & 7.847 & 9,99 & 4.832 & 6,15 & 162,39 \\
\hline Pardos (2) & 7.981 & 10,16 & 8.810 & 11,22 & 90,59 \\
\hline Pretos & 33.861 & 43,12 & 15.187 & 19,34 & 222,96 \\
\hline Subtotal & 49.689 & 63,29 & 28.829 & 36,71 & 172,35 \\
\hline TOTAL & \multicolumn{4}{|c|}{78.518} & \\
\hline \multicolumn{6}{|l|}{1821} \\
\hline Brancos & 6.645 & 8,79 & 6.691 & 8,85 & 99,31 \\
\hline Mulatos & 11.310 & 14,96 & 18.192 & 24,07 & 62,17 \\
\hline Pretos & 19.291 & 25,52 & 13.441 & 17,79 & 143,71 \\
\hline Subtotal & 37246 & 49,29 & 38324 & 50,71 & 97,18 \\
\hline TOTAL & \multicolumn{4}{|c|}{75.570} & \\
\hline Taxa de crescimento $1776-1821(\%)$ & & & & & \\
\hline
\end{tabular}

Fonte: AHU /MG - Cx: 112, Doc: 11; Eschwege (1899, p. 774).

(1) Número de homens para cada 100 mulheres.

(2) Quanto às categorias raciais, a única diferença entre os mapas de 1776 e 1821 é a utilização do vocabulário pardos/as e mulatos/as, respectivamente, para representar o mesmo grupo.

Quando em 1804 se lançou um donativo para ajudar a custear as despesas militares do Reino, a comarca contribuiu com $21,35 \%$ do que foi arrecadado em toda capitania, bem abaixo da comarca do Rio das Mortes responsável pela contribuição de 35,92\%. Este é um dado importante porque o cálculo da contribuição era feito à semelhança do imposto de capitação que vigorou de 1736 a $1750 .{ }^{14}$ Nesse sentido, parece bastante óbvia a superio-

\footnotetext{
$\overline{14}$ Um imposto per capita calculado à proporção do número de escravos.
} 
ridade económica desta última. Porém, na listagem dos que fizeram “doações voluntárias, excedendo a quota para eles fixada", Vila Rica contava com 13 indivíduos "mais favorecidos da fortuna" e mais solidários, diga-se de passagem, enquanto na comarca do Rio das Mortes contava-se apenas um (MATHIAS, 1969, VI).

Fortunas concentradas e consolidadas na capital da capitania e dispersas na comarca do Rio das Mortes? Talvez. Mas o que importa observar, como sugerem os números da contribuição (obrigatória), é que no Rio das Mortes o contingente de escravos era superior. Informação indispensável em nosso caso por possuirmos apenas um mapa demográfico para esta localidade que nos fornece dados sobre o estatuto jurídico da sua população.

TABELA 6

População, por género, segundo cor Comarca de Rio das Mortes - 1776-1821

\begin{tabular}{|c|c|c|c|c|c|}
\hline \multirow{2}{*}{ Cor } & \multicolumn{2}{|c|}{ Homens } & \multicolumn{2}{|c|}{ Mulheres } & \multirow{2}{*}{$\begin{array}{c}\text { Razão de sexo } \\
\text { (1) }\end{array}$} \\
\hline & $\mathrm{N}$ & $\%$ & $\mathrm{~N}$ & $\%$ & \\
\hline \multicolumn{6}{|l|}{1776} \\
\hline Brancos & 16.277 & 19,66 & 13.649 & 16,49 & 119,25 \\
\hline Pardos (2) & 7.615 & 9,20 & 8.179 & 9,88 & 93,10 \\
\hline Pretos & 26.199 & 31,65 & 10.862 & 13,12 & 241,19 \\
\hline Subtotal & 50.091 & 60,51 & 32.690 & 39,49 & 153,23 \\
\hline TOTAL & \multicolumn{4}{|c|}{82.781} & \\
\hline \multicolumn{6}{|l|}{1821} \\
\hline Brancos & 42.420 & 19,88 & 35.355 & 16,55 & 119,98 \\
\hline Mulatos & 23.973 & 11,23 & 23.760 & 11,12 & 100,89 \\
\hline Pretos & 59.341 & 27,80 & 28.688 & 13,42 & 206,99 \\
\hline Subtotal & 125.734 & 58,88 & 87.803 & 41,12 & 143,20 \\
\hline TOTAL & \multicolumn{4}{|c|}{213.537} & \\
\hline $\begin{array}{l}\text { Taxa de crescimento } \\
1776-1821(\%)\end{array}$ & & & & & \\
\hline
\end{tabular}

Fonte: AHU /MG - Cx: 112, Doc: 11; Eschwege (1899, p. 774).

(1) Número de homens para cada 100 mulheres.

(2) Quanto às categorias raciais, a única diferença entre os mapas de 1776 e 1821 é a utilização do vocabulário pardos/as e mulatos/as, respectivamente, para representar o mesmo grupo.

Vila Rica, entretanto, apresentou redução de cerca de $40 \%$ de cativos, em particular os do sexo masculino, e também das pretas (Tabela 7). Tendo sofrido o declínio da extração do ouro, provavelmente não necessitou recompor sua mão de obra escrava para outras atividades. Se, em 1776, os cativos correspondiam a $56,16 \%$ (uma porcentagem mais elevada do que a média da capitania), mais de 40 anos depois eles eram 35,64\%. Entretanto, era este praticamente o valor registrado em 1821 para a capitania como um todo e para a comarca do Rio das Mortes, separadamente. Mas Vila Rica não acompanhou as transformações da mesma forma que as outras comarcas. Se os escravos ainda mantinham um porcentual acima dos $35 \%$, é preciso não esquecer que, entre os livres, alguns grupos tiveram uma queda em termos absolutos, como foi o caso dos homens brancos e pardos. A par desta característica tão singular, na sociedade de Vila Rica as mulheres cresceram em termos absolutos e relativos, chegando mesmo a contribuir para que a razão de sexo estivesse muito próximo dos 100 . Nesta região também o crescimento do número de mulatas forras é maior do que todos os demais grupos (por género e cor), confirmando 
mais esta característica de Minas Gerais, que, no entanto, será contrariada na comarca do Rio das Mortes. Ao que parece, é a comarca de Vila Rica que mais se aproxima do que foi vivido em Minas Gerais neste intervalo de 1776-1821: o aumento da população feminina e do grupo racial dos pardos e a redução em termos proporcionais do número de cativos, ainda que tudo isso ocorresse de forma muito mais extremada.

A comarca do Rio das Mortes, ao contrário, viveu um período de grande crescimento económico e demográfico, cuja exuberância os números bem indicam. Em meio século, a população cresceu cerca de duas vezes e meia (taxa de 157,9\%), em boa medida por conta da imigração de pessoas classificadas com todas as cores, provenientes provavelmente não apenas de outros continentes, mas também de outras capitanias americanas. Isso explica o fato de a taxa de masculinidade ter se mantido muito alta, equivalente à de 1776. 0 aumento da proporção das mulheres só se observou no grupo dos pretos e, mesmo assim, a razão de sexo era tão elevada $(206,99)$ que se trata apenas de uma pequena redução da diferença numérica entre os géneros no interior deste grupo. Por outro lado, também aqui o grupo que mais cresceu foi o dos pardos/as, assim como o das mulheres brancas, como vimos que ocorria para Minas Gerais na sua totalidade. Com a expansão da agropecuária em função do mercado carioca a partir de 1808, Rio das Mortes irá concentrar a maior parte da população de Minas, com $46,77 \%$ dos escravos da capitania a viver nesta comarca. Trata-se de inversão do eixo económico de Vila Rica para Rio das Mortes que se reflete nos dados demográficos da unidade administrativa a que pertenciam: Minas Gerais (ALMEIDA, 2005, p. 141).

TABELA 7

População cativa, por género

Comarcas de Vila Rica e Rio das Mortes - 1776-1821

\begin{tabular}{|c|c|c|c|c|c|c|}
\hline \multirow[t]{2}{*}{ Anos } & \multicolumn{3}{|c|}{ Vila Rica } & \multicolumn{3}{|c|}{ Rio das Mortes } \\
\hline & Homens & Mulheres & $\%(1)$ & Homens & Mulheres & $\%(1)$ \\
\hline 1776 & 32.271 & 11.815 & 56,14 & & & \\
\hline Total & \multicolumn{2}{|c|}{44.086} & & & & \\
\hline 1821 & 16.963 & 9.973 & 35,64 & 58.087 & 26.908 & 39,81 \\
\hline Total & \multicolumn{2}{|c|}{26.936} & & \multicolumn{2}{|c|}{84.995} & \\
\hline
\end{tabular}

Fonte: AHU /MG - Cx: 112, Doc: 11; Eschwege (1899, p. 774).

(1) Em relação à população total da respectiva comarca.

\section{Conclusões}

Os mapas de população produzidos para Minas Gerais colonial são escassos mas suficientemente informativos de 45 anos da sua história e das diferenças existentes entre suas comarcas, em particular as de Vila Rica e Rio das Mortes. A forma como se processou o crescimento da população, nestes anos, suscitou mudanças consideráveis, alterando em parte a configuração da sociedade mineira. A ponderação aqui é mais do que necessária. Afinal, como vimos, Minas Gerais tornou-se mais mestiça e com uma porcentagem 
maior de mulheres, em todos os grupos sociais, assim como reduziu em termos relativos o número de escravos de ambos os sexos. Todavia, se o seu crescimento se processou de uma forma diversa da que vinha ocorrendo até então, a capitania manteve em 1821 muitas das características que possuía em 1776. Continuou a ter uma população eminentemente de cor, com o predomínio neste grupo dos homens classificados como pretos, bem como a ser maioritariamente masculina e com o maior plantel de cativos do Brasil, em termos absolutos. Ou seja, as tendências de evolução da população mineira não bastaram para desfazer as características globais desta sociedade.

A evolução deste crescimento populacional ajuda a perspectivar as transformações económicas em um período no qual a decadência da produção aurífera foi uma constante, assim como a capacidade de Minas Gerais de se recompor e de se dinamizar (em grande parte devido à diversificação económica de há muito marcante). Com uma produção voltada eminentemente para o mercado interno e, a partir de 1808, também para o abastecimento da Corte no Rio de Janeiro, já não havia tanta necessidade de importar mão de obra escrava africana com a mesma intensidade do que no auge minerador. Como consequência, reduziu-se a imigração deste grupo, visível no exíguo crescimento do número de pretos, como eram referidos, e na diminuição em termos absolutos dos escravos. Também a imigração de homens brancos, para usar a terminologia das fontes, vindos sobretudo diretamente de Portugal mas também de outras capitanias, sofreu uma contração dada a falta de atrativos económicos na região comparáveis ao ouro.

Assim, é seguro dizer que o aumento populacional das Minas Gerais, neste período, deveu-se sobretudo a um crescimento natural responsável pela maior miscigenação e pelo aumento do número de mulheres. Não há dúvida de que estas mudanças foram de grande monta mesmo que não tenham alterado o predomínio dos grupos, divididos por cor/género, globalmente. Tomando um exemplo entre tantos, a feminização da sociedade mineira não reverteu o predomínio de homens, embora elas tenham passado de $37,6 \%$ para 45,2\% da população, ou seja, quase chegaram a atingir uma igualdade numérica.

As transformações produtivas e a dinamização de outras regiões, que não a comarca de Vila Rica, mudaram a sociedade mineira, assim como as transformações advindas de um contexto mais global que atingiram todo o Império luso, sobretudo a América portuguesa. As conexões que se sugeriram entre razão de sexo, estatuto jurídico e cor da população, por um lado, e crescimento natural e imigração, por outro, constituem uma das vertentes que se exploraram neste estudo.

\section{Referências}

Arquivo Histórico Ultramarino - fontes manuscritas

Capitania da Bahia:

AHU_ACL_CU_005-01, Cx.55, Doc 10700-10701. Disponível em: «http://colonialpopulations.fcsh. unl.pt>. Acessado em: 12 dez. 2016. 
Capitania de Goiás:

AHU_ACL_CU_008,Cx:27, Doc:1737

Capitania do Maranhão:

AHU_ACL_CU 009; Cx:50, Doc:4951

Capitania de Minas Gerais:

Cx:42, Doc:62

Cx:42, Doc:63

Cx:44, Doc:85

Cx:55, Doc:39

Cx:70, Doc:41

Cx:98, Doc:53

Cx:108, Doc:9

Cx:112, Doc:11

Cx:120, Doc:15

Cx:144, Doc:18

Cx:147, Doc:55

Cx:154, Doc:42

ALDEN, D. The population of Brazil in the late century: a preliminary study. Hispanic American Historical Review, v. 43, n. 2, p. 176-177, May 1963.

ALENCASTRE, J. M. P. Annaes da Provincia de Goyaz. Revista do Instituto Historico Geografhico e Ethnografhico do Brasil, tomo XXVII, parte segunda, 1864. Disponível em: 〈https://drive.google. com/file/d/0B_G9pg7CxKSsdlF0eUdheWdkd1k/view>. Acesso em: 2 nov. 2016.

ALMEIDA, C. M. C. De Vila Rica ao Rio das Mortes: mudança do eixo econômico em Minas colonial. Locus: Revista de História, v. 11, n. 1/ 2, p. 137-160, 2005.

Ricos e pobres em Minas Gerais. Produção e hierarquização social no munco colonial, 1750-1822. Belo Horizonte: Argumentum, 2010.

BERGARD, L. Slavery and the economic and demographic history of Minas Gerais, Brazil, 17201888. New York: Cambridge University Press, 1999.

BOTELHO, T. R. Família e escravidão em uma perspectiva demográfica; Minas Gerais (Brasil), século XVIII. In: LIBBY, D. C.; FURTADO, J. F. (Org.). Trabalho livre, trabalho escravo: Brasil e Europa, séculos XVIII e XIX. São Paulo: Annablue, 2006. p. 195-222.

. Estimativas da população. In: X CONGRESSO BRASILEIRO DE HISTÓRIA ECONÔMICA. Anais... Juiz de Fora, MG: Universidade Federal de Juiz de Fora, 9 a 11 de setembro de 2013.

População e escravidão nas Minas Gerais, c. 1720. In: XII ENCONTRO NACIONAL DE ESTUDOS DE POPULAÇÃO. Anais... Caxambu: Abep, 2000. Disponivel em: «http://www.abep.org. $\mathrm{br} /$ abeporgb/publicacoes/index.php/anais/issue/view/32/showToc>. Acesso em: 27 nov. 2016.

BOTELHO, T. R.; PAIVA, C. A. Políticas de população no período joanino. In: XVI ENCONTRO NACIONAL DE ESTUDOS POPULACIONAIS. Anais... Caxambu: Abep, 2008. Disponível em: «http://www.abep. nepo.unicamp.br/encontro2008/docsPDF/ABEP2008_1404.pdf). Acesso em: 25 nov. 2016.

BUCCIFERRO, J. A forced hand: natives, Africans, and the population of Brazil, 1545-1850. Revista de Historia Económica, v. 31, n. 2, p. 285-317, September 2013. Disponível em: 〈http://journals. cambridge.org/abstract_S0212610913000104〉. Acesso em: 12 dez. 2016.

"CARTA do Sr. Martinho de Mello e Castro com a relação que Sua Majestade manda formar dos habitantes desta Capitania”. Revista do Instituto Histórico Geográfico de Minas Gerais, Belo Horizonte, v. X, p. 421-3, 1963. 
COSTA, I. N. Vila Rica: população (1719-1826). São Paulo: IPEUSP, 1979.

COSTA, I. N.; LUNA, F. V. Minas colonial: economia e sociedade. São Paulo: FIP-USP, 1982.

CURTO, J. C.; GERVAIS, R. R. A dinâmica demográfica de Luanda no contexto do tráfico de escravos do Atlântico Sul, 1781-1844. Topoi, Revista de História, p. 85-138, mar. 2002. Disponível em: 〈http://www.revistatopoi.org/numeros_anteriores/Topoi04/04_artigo04.pdf〉. Acesso em: 16 dez. 2016.

ESCHWEGE, G. B. de. Notícias e reflexões estatísticas da província de Minas Gerais. Revista do Arquivo Público Mineiro, Belo Horizonte, v. 4, p. 737-762, 1899.

FAUSTO, B. História do Brasil. 2. ed. São Paulo: Edusp, 1995.

FURTADO, J. F. Novas tendências da historiografia sobre Minas Gerais no período colonial. História da Historiografia, v. 2, p. 116-162, 2009. Disponível em: 〈https://www.historiadahistoriografia. com.br/revista/article/download/11/11). Acesso em: 11 out. 2016.

GUEDES, R.; FRAGOSO, J. (Org.). História social em registros paroquiais (Sul-Sudeste do Brasil, séculos XVIII-XIX). Rio de Janeiro: Mauad X, 2016.

KLEIN, H. S.; LUNA; F. V. Slavery in Brazil. Cambridge: Cambridge University Press, 2010.

LIBBY, D. C. Transformação e trabalho numa economia escravista, Minas Gerais no século XIX. São Paulo: Brasiliense, 1988.

LIBBY, D. C. et al. História da família no Brasil (séculos XVIII, XIX e XX): novas análises e perspectivas. Belo Horizonte: Fino Traço Editora, 2015.

LIBBY, D. C.; BOTELHO, T. Filhos de Deus. Batismos de crianças legítimas e naturais na Paróquia de Nossa Senhora do Pilar de Ouro Preto, 1712-1810. Varia História, v. 20, n. 31, p. 69-96, jan. 2003.

LIBBY, D. C. As populações escravas das Minas Gerais: um balanço preliminar. In: RESENDE, M. E. L. de; VILLALTA, L. C. (Org.). As Minas setecentistas. Belo Horizonte: Autêntica, Companhia do Tempo, 2007. p. 407-438.

LIMA JÚNIOR, A. A capitania de Minas Gerais. Belo Horizonte/São Paulo: Editora Itatiaia/Editora da Universidade de São Paulo, 1978.

LINHARES, M. Y. L. O Brasil no século XVIII e a idade do ouro: a propósito da problemática da decadência. In: SEMINÁRIO SOBRE A CULTURA MINEIRA NO PERÍODO COLONIAL. Anais... Belo Horizonte: Conselho Estadual de Cultura de Minas Gerais, 1979.

LIVI-BACCI, M. 500 anos de demografia brasileira: uma resenha. Revista Brasileira de Estudos de População, v. 19, n. 1, jan./jun. 2002. Disponível em: 〈https://www.rebep.org.br/revista/ search/search?simpleQuery=bacci\&searchField=query>. Acesso em: 2 jan. 2017.

MARCÍLIO, M. L. A população do Brasil colonial. In: BETHELL, L. (Org.). História da América Latina - América Latina Colonial. São Paulo: Edusp, v. 2, 2004. p. 311-338.

MATHIAS, H. G. Um recenseamento na capitania de Minas Gerais. Vila Rica -1804. 1. ed. Rio de Janeiro: Arquivo Nacional, 1969.

MATOS, P.; SOUSA, P. S. A estatística da população na América portuguesa, 1750-1820. Memória, Revista Digital de Historia y Arqueología desde el Caribe Colombiano, n. 25, p. 73-103, enero/abril 2015. Disponível em: 〈https://dialnet.unirioja.es/ejemplar/392945〉. Acesso em: 17 nov. 2016.

MÓL, C. C. Vendendo desordens e comprando liberdade: a inserção das mulheres forras em Vila Rica, 1750-1800. In: XI SEMINÁRIO SOBRE A ECONOMIA MINEIRA. Anais... Diamantina, MG: Cedeplar, 2004. Disponível em: 〈http://www.cedeplar.ufmg.br/diamantina2004/textos/ D04A002.PDF>. Acesso em: 16 dez. 2016. 
MONTEIRO, N. G. A circulação das elites no império dos Bragança (1640-1808): algumas notas. Tempo, v. 14, n. 27, p. 51-67, 2009. Disponivel em: 〈http://www.historia.uff.br/tempo/artigos_ dossie/v14n27a05.pdf〉. Acesso em: 13 nov. 2016.

MORAES, F. B. de. De arraiais, vilas e caminhos: a rede urbana das Minas coloniais. In: RESENDE, M. E. L. de; VILLALTA, L. C. (Org.). As Minas setecentistas. Belo Horizonte: Autêntica, Companhia do Tempo, 2007. p. 55-86.

PAIVA, E. F. Escravos e libertos em Minas Gerais no século XVIII. São Paulo: Annablume, 1995. POPULAÇÃO da Província de Minas Gerais. Revista do Arquivo Público Mineiro, Belo Horizonte, ano 4, p.294-296, 1899.

ROCHA, J. J. Geografia histórica da capitania de Minas Gerais (1776). Belo Horizonte: Fundação João Pinheiro, Centro de Estudos Históricos e Culturais, 1995.

RUSSELL-WOOD, A. J. R. Escravos e libertos no Brasil colônia. Rio de Janeiro: Civilização Brasileira, 2005.

SANTOS, A. C. A. Aritmética política e a administração do estado português na segunda metade do século XVIII. In: DORÉ, A.; SANTOS, A. C. de A. (Org.). Temas setecentistas: governos e populações no Império português. Curitiba: UFPR/Fundação Araucária, 2009. p. 143-152.

SOUZA, L. M. O Sol e a sombra. São Paulo: Companhia das Letras, 2006.

STUMPF, R. G. Filhos das Minas, americanos, portugueses. Identidades coletivas na capitania das Minas Gerais (1763-1792). São Paulo: Editora Hucitec, 2010.

Os cavaleiros do ouro e outras trajetórias nobilitantes nas Minas setecentistas. Belo Horizonte: Editora Fino Traço, 2014.

WAGNER, A. P. Política e população no Império português: Moçambique no último quartel do século XVII. In: DORÉ, A.; SANTOS, A. C. de A. (Org.). Temas setecentistas: governos e populações no Império português. Curitiba: UFPR/Fundação Araucária, 2009. p. 399-411.

\section{Sobre a autora}

Roberta Giannubilo Stumpf é doutora em História Social pela Universidade Federal de Brasília (UnB). Subdiretora e investigadora integrada do Centro de Humanidades da Faculdade de Ciências Sociais e Humanas da Universidade Nova de Lisboa/Universidade dos Açores.

\section{Endereço para correspondência}

Rua Borges Carneiro, 19 2DTO

1200-617 - Lisboa, Portugal

\section{Abstract}

Minas counted in number: Capitania of Minas Gerais and the Demographic sources (1776-1821)

The "population tables" available since the 1770's shed new light on a period in the history of Minas Gerais which was particularly important for the transformations experienced in very different fields. Based on information gathered in these documents, this paper focuses on the transformations of Minas Gerais' economy as well as the redefinition of that society in a period 
in which captaincy gains a new profile, yet maintaining its fundamental role in the dynamics of the center-south of Portuguese America.

Keywords: Mining economy. Colonial populations. Population statistics. Brazil. 18-19th centuries

\section{Resumen}

Minas contada en números: la capitanía de Minas Gerais y las fuentes demográficas (1776-1821)

Los “mapas de población” producidos a partir de la década del setenta del siglo XVIII contribuyen al análisis de un período de la historia de Minas Gerais que fue especialmente importante por todos los cambios experimentados en ámbitos muy diferentes. Con base en los datos que proporcionan estos documentos, el presente artículo analiza las transformaciones en la economía minera y la redefinición de aquella sociedad en un período en el cual Minas Gerais gana un nuevo perfil, al mismo tiempo que mantiene su papel fundamental en las dinámicas centro-sur de la América portuguesa.

Palabras clave: Economía minera. Población colonial. Estadísticas de población. Brasil. Siglos XVIII-XIX.

Recebido para publicação em 30/01/2017 Aceito para publicação em 13/09/2017 